\title{
ESPIRITUALIDADE E SAÚDE: ENSAIO SOBRE NOVAS ARTICULAÇÓES ENTRE RELIGIÃO E CIÊNCIA ${ }^{1}$
}

Airton Luiz Jungblut ${ }^{2}$

Resumo: $\mathrm{O}$ artigo aborda analiticamente algumas das questóes que surgem como consequência das novidades trazidas para o campo religioso contemporâneo da crescente penetração de práticas terapêuticas relacionadas à religião em espaços próprios das ciências da saúde (hospitais, clínicas, consultórios, postos de saúde, etc.). Busca-se compreender como, através dessa aproximação entre religiáo e um front da ciência moderna, são tensionados alguns aspectos destes dois campos que eram tidos, até bem pouco tempo, como inconciliáveis. Nesse exercício é dada atenção especial ao conceito de "espiritualidade", entendida como uma propriedade inata às pessoas que é remetida, pelas ciências da saúde, à "natureza humana".

Palavras-chave: Espiritualidade; Ciência e Religião; Religiosidade Contemporânea; Terapias Alternativas.

\begin{abstract}
The article analytically addresses some of the issues that arise as a result of the novelties brought to the contemporary religious field by the increasing penetration of religious-related therapeutic practices into the realm of health sciences (hospitals, clinics, doctor's offices, health centers, etc.). It is an effort to understand - through this approach between religion and a front of modern science - how tension is formed between some aspects of these two fields, which
\end{abstract}

1 Como citar: JUNGBLUT, Airton Luiz. Espiritualidade e saúde: ensaio sobre novas articulaçốes entre religiáo e ciência. Debates do NER, Porto Alegre, v. 1, n. 37, p. 201-216, 2020.

2 Airton era professor do Programa de Pós-Graduação em Ciências Sociais da Pontifícia Universidade Católica do Rio Grande do Sul, Porto Alegre, Brasil. Este trabalho representa uma pequena homenagem ao pesquisador, que construiu parte de sua trajetória no NER/PPGAS/UFRGS. Ele faleceu no dia 29 de junho de 2020.

Debates do NER, Porto Alegre, ano 20, N. 37, P. 20 I-2 I 6, Jan./JUl. 2020 
were, until recently, considered irreconcilable. In this exercise, special attention is given to the concept of "spirituality", understood as an innate property to people and associated by the health sciences to "human nature".

Keywords: Spirituality; Science and Religion; Contemporary Religiosity; Alternative Therapies.

\section{INTRODUÇÃO}

O termo "espiritualidade", conforme uso comum ou mesmo acadêmico carrega consigo uma certa imprecisão conceitual. Ele aparece, mais frequentemente, associado a formas menos elaboradas de vivência e/ou percepção religiosa. Ocupa parte daquela zona nebulosa onde gravitam formas pouco precisas de modalidades religiosas. A palavra tem o sufixo "-idade" que é adicionado a adjetivos com a finalidade de formar substantivos que expressam a ideia de situação, condição, qualidade, modo de ser, estado, propriedade. Trata-se, portanto, de um termo que alude a algo "espiritual" que as pessoas ou coisas, vinculadas ou náo a uma modalidade religiosa, possuem, carregam consigo, consciente ou inconscientemente.

José Jorge de Carvalho, numa das raras definições acadêmicas sobre espiritualidade, atenta para as expressôes "manifestas" e "caladas":

[...] espiritualidade é, para mim, a maneira como um determinado indivíduo internaliza, desenvolve, de um modo sempre idiossincrático, aquela particular via ou modelo de união (ou de re-ligação, para lembrarmos a origem do termo) proposto pela religião a que adere. Assim, espiritualidade já implica uma dimensão de subjetividade trabalhada, de experiência que transcende a norma ou a expectativa formal da comunidade. Enfim, pode-se ser religioso, no sentido de assiduidade de participação, sem que se tenha uma espiritualidade muito desenvolvida.

[...] além das espiritualidades manifestas, mutuamente comunicadas, estão as espiritualidades caladas, circunscritas, fechadas em si mesmas (Carvalho, 1992, p. 4, 7). 
Uma rápida busca por esse termo na Web nos aponta para algo curioso: "espiritualidade" aparece muito associada a tratamentos "alternativos" realizados em espaços de saúde (hospitais, clínicas, consultórios, postos médicos, etc.). E eis que um termo aparentemente "inocente" revela todo um interessantíssimo empreendimento semântico, ou mesmo uma "província de significados" (Schutz, 1979, p. 248-249), a ver com coisas curiosas que acontecem no campo religioso contemporâneo.

Tal descoberta não é nova no Brasil. Pesquisadores como Waleska de Araújo Aureliano e Rodrigo Toniol já, há alguns anos, vêm analisando essa curiosa simbiose entre terapias algo religiosas e procedimentos de cura médica.

Segundo nos informa Aureliano (2011), o termo "espiritualidade", no Brasil, vem se vinculando a adoçáo gradativa de orientaçôes da Organizaçáo Mundial da Saúde (OMS) de disponibilizar aos consumidores de serviços públicos de saúde tanto a chamada a Medicina Tradicional (MTs), Medicina Alternativa e Complementar (MACs). Segundo a autora, esse processo

[...] fez com que certos recursos terapêuticos antes restritos aos espaços alternativos de cura (sejam eles os tradicionais centros espíritas ou os modernos centros holísticos da Nova Era) estejam gradualmente sendo incorporados ao sistema nacional de saúde, tanto público, quanto privado (Aureliano, 2011, p. 183).

A autora informa, ainda, que em 2006 o Governo Federal brasileiro lançou o Plano Nacional de Práticas Integrativas e Complementares (PNPIC), que trata da inclusão de "terapias não-biomédicas" no SUS (Sistema Único de Saúde) (Aureliano, 2011, p. 183), entre as quais: antroposofia, o Reiki, o termalismo-crenoterapia, etc.

Rodrigo Toniol (2015a, 2015b, 2017), por sua vez, tem contribuído com uma ampla análise a respeito de como esse processo tem ocorrido e monitorado o impacto no campo médico. $\mathrm{O}$ autor nos apresenta aos pioneiros na criação dessa articulação entre saberes médicos e religiosos, que tem como corolário a emergência do índice "espiritualidade". Refere 
e demonstra através de quadros evolutivos o boom de pesquisas e publicaçôes científicas que têm sido produzidas nas últimas décadas. Trata-se de um empreendimento acadêmico que avalia a eficácia da ação das MTs e MACs sobre a "espiritualidade" de pacientes atendidos em espaços médicos convencionais. É realmente surpreendente essa mobilização em proveito da mensuração da eficácia das terapias direcionadas à espiritualidade dos pacientes que setores acadêmicos vinculados às ciências médicas movem, sendo que na grande maioria dos casos é para atestar eficácia desses procedimentos. Descobre-se, através disso, um certo desembaraço das ciências médicas para com a, outrora, intangível dimensão espiritual da doença.

\section{PROXIMIDADES ENTRE RELIGIÃO E CIÊNCIA}

Já é de conhecimento geral que serviços de cura, minimização de sintomas de doenças e paliativismos, etc., oferecidos por agências religiosas no Brasil promove a aproximaçáo entre estas e seus potenciais adeptos, fieis, clientes. Cândido Procópio, já em 1961, afirmava que a "esperança de cura" seria o "motivo primordial de aproximaçáo" de pessoas doentes às chamadas "práticas mediúnicas" (Procópio, 1961, p. 94).

Também já sabemos que adeptos e praticantes das chamadas religióes de Nova Era (New Age), principalmente em função da dimensão "terapêutica" destas, esboçam uma relação menos tensa, mais amigável, com a Ciência moderna. Já em 1986, Robert Bellah, estudioso deste campo religioso, afirmava:

Muito embora a ciência seja vista de forma ambivalente e os perigos do progresso científico sejam conscientemente temidos por muitos membros dos grupos estudados por nós, a ciência enquanto tal não é rejeitada. Há uma crença de que parte significativa daquilo que é experimentado pode ser validado cientificamente. Na verdade, os grupos de potencial humano (e a Meditaçáo Transcendental) acreditam que seus ensinamentos estáo de acordo com a ciência, no sentido em que ela é amplamente entendida. O estudo da fisiologia 
do cérebro durante a meditação é considerado não como uma ameaça, mas como um suporte para a prática religiosa (Bellah, 1986, p. 31, grifo nosso).

Também Colin Campbell, ao tratar de religióes e religiosidades representantes do que ele chama de "teodicéia oriental", lócus classificatório de muitas das terapias alternativas que tratamos aqui, vê articulaçôes estratégicas entre ciência e este tipo de religiosidade mística e difusa embalada pela Nova Era:

[A] teodicéia oriental tem uma evidente vantagem sobre a ocidental tradicional na medida em que tanto é menos vulnerável ao ataque da ciência (visto que não é baseada em verdades literais, históricas) como é mais compatível com o pensamento moderno em sua aparente abertura e individualismo. Esse individualismo extremo, juntamente com o anti-dualismo e a relativização das pretensōes de verdade, torna-a um alvo muito difícil para o ataque dos racionalistas e cientistas. De fato, a religiáo mística oriental tende a usar o ataque secular, humanístico sobre a religião tradicional em benefício próprio; ao mesmo tempo em que também se aproveita das incertezas e disputas no interior das ciências para promover afirmaçóes místicas (Campbell, 1997, p. 18).

No caso em questão, aqui, assiste-se a novos movimentos de aproximação entre ciência e religiáo ou, pelo menos, entre ciência e alguns subprodutos da religiosidade contemporânea. Olhando para esses movimentos veem-se sinais de amistosidade sendo emitidos do campo religioso para o campo científico. A novidade trazida pela noção de "espiritualidade", livre trafegando por certas áreas do campo das ciências da saúde, é que, agora, já se pode observar, também, o campo científico emitindo sinais amistosos em direção ao campo religioso.

Nesse processo, vejo como importante a ideia ventilada no campo das ciências médicas de que há uma "espiritualidade" que, inelutavelmente, faz parte da condição humana, que "é parte da natureza da pessoa" e que nada tem a ver com as "escolhas individuais", com "adesão" (Toniol, 2015a, p. 205). Trata-se, como capta Toniol, do "fundamento espiritual da pessoa, forjado, ao fim e ao cabo, na natureza humana” (Toniol, 2017, p. 155). De 
uma "espiritualidade [que seria] parte da natureza da pessoa, enquanto a religiấo [seria] a expressão de escolhas individuais” (Toniol, 2017, p. 156). E isso, previsivelmente, não se faz sem que a ideia de "holismo" seja acionada:

A dimensão espiritual incide tanto na saúde física como mental dos indivíduos. Isso é, espiritualidade tem a capacidade de transpassar as possíveis fronteiras entre essas "partes", encarnando de modo emblemático o caráter holístico da saúde humana (Toniol, 2015b, p. 126-127).

Ora, esses afagos que as ciências da saúde estariam a fazer a alguns subprodutos da religiosidade contemporânea mostram algo instigante: uma rearticulação entre religiáo e ciência que não deixa de por em xeque a eficácia daquele ato iluminista emblematicamente produzido pelo naturalista sueco Carlos Lineu através do qual, segundo Roque Laraia, o homem é "derrubado de seu pedestal sobrenatural" e colocado "bem no meio da natureza, na ordem dos primatas". Esse "ato iconoclasta" ocorre "no contexto do século XVIII, quando a explicação da natureza do homem é fortemente influenciada pelo desenvolvimento da biologia” (Laraia, 2005, p. 321). Assim como essa naturalização do homem, antes considerado "à parte da natureza" (Laraia, 2005, p. 321), a sua dimensáo espiritual deixaria, por muito tempo, de ser algo com que a ciência se ocupasse.

Dessa forma, não deixa de ser curioso quando se vislumbra esforços das ciências da saúde para realojar a dimensão espiritual no conjunto do que é tomado por "ser humano", produzindo, de forma tão pacífica, essa articulação conceitual entre o espiritual e o natural humano. Essa "natureza humana" dotada de "espiritualidade" emergida, como discurso, de alguns setores das ciências da saúde é, certamente, um fenômeno recente e complexifica ainda mais a já intrincada relação entre modernidade e religião. 


\section{A QUESTÃO DA VALIDAÇĀO \\ DA CRENÇA NA ESPIRITUALIDADE}

Em se tratando de crer, há sempre o velho problema da "validação" da crença individual através do vínculo com alguma modalidade religiosa, do necessário sentimento de "dependência tutelar que vincula o fiel ao seu culto”, segundo Durkheim (1989, p. 495) e que animaria a religião de um modo geral. Os indivíduos sempre querem que aquilo no qual creem tenha pelo menos um mínimo de aceitabilidade social, que seja compartilhado como sentimento social, que seja experimentado por outros e que estes lhe atestem através de testemunhos e outras práticas a aceitabilidade de suas crenças e práticas religiosas.

Como deve ocorrer a validação da crença religiosa no mundo contemporâneo? Em sua tentativa de construir uma classificaçáo típica-ideal dos diversos "regimes de validação do crer", disponíveis nas várias modalidades religiosas existentes, Danièle Hervieu-Léger (2008, p. 163) nos apresenta as seguintes quatro validaçóes:

\begin{tabular}{|c|c|c|}
\hline Regime de validação & Instância de validaçáo & Critério de validaçáo \\
\hline Institucional & A autoridade institucional qualificada & A conformidade \\
\hline Comunitária & O grupo como tal & A coerência \\
\hline Mútua & O outro & A autenticidade \\
\hline Autovalidação & O indivíduo, ele mesmo & A certeza subjetiva \\
\hline
\end{tabular}

Esses “regimes de validação", em formato típico-ideal, foram pensados para esgotar as possibilidades desse exercício tão importante no universo da religiáo que é atestar credibilidade ao que se crê. O levantamento que Rodrigo Toniol (2015b) fez de publicações internacionais, utilizando o Sistema Online de Busca e Análise de Literatura Médica (Medline), em que os termos "espiritualidade" e "saúde" aparecem associados, torna visível o que 
poderíamos considerar um novo "regime de validaçáo" da crença religiosa. Vejamos os dados trazidos por Toniol (2015b, p. 116-117).

Entre 1970 e 1979 apenas um artigo mencionou o "fator espiritualidade". $\mathrm{Na}$ década seguinte o número saltou para 89 ocorrências. Entre 1990 e 1999 foram 293 e, finalmente, entre 2000 e 2009 o aumento foi emblemático, 2513 trabalhos relacionaram espiritualidade à saúde. A evidente expansão no número de periódicos, livros e textos científicos nesse período não diminui a relevância desses números, pelo contrário, a reforça. $\mathrm{Na}$ comparação entre o crescimento percentual da totalidade de textos indexados na Medline e dos materiais que estabelecem a associaçáo aqui tematizada, encontramos os seguintes dados: na comparação entre 1980 e 1990 o número geral de publicaçôes cresceu 177\% e o específico (espiritualidade + saúde) 229\%; nas décadas seguintes o aumento foi de $55 \%$ para um e $757 \%$ para o outro. A progressão nos números de publicaçóes e os significativos incrementos em todos os intervalos é, de fato, um argumento contumaz [...] para fundamentar a percepção generalizada de que há um maior interesse das ciências médicas pela espiritualidade.

No Brasil, uma ligeira checagem em plataformas de textos acadêmicos, como "Scielo" e "Google Acadêmico" é o bastante para verificar a associação muito recorrente entre os termos "espiritualidade" e "saúde". Olhando um pouco mais atentamente para essa literatura acadêmica, pode-se também verificar que, em grande parte, ela é composta por textos que buscam algum tipo de mensuração sobre a eficácia das terapias que tratam da "espiritualidade" de vários tipos de pacientes que estão a receber cuidados das ciências da saúde. Em muitos casos, esses olhares acadêmicos sobre a "espiritualidade" desses pacientes atestam "resultados positivos" e acabam por validar sua utilidade.

Temos aqui algo novo e curioso. Um front da ciência - que, como se sabe, sempre desdenhou o que náo pode ser esquadrinhado cartesianamente - testemunhando favoravelmente à religião. Trata-se de um novo "regime de validação" que emerge. Agora além da validação "institucional", 
“comunitária”, "mútua” e "autovalidação" temos, também, a validação científico-acadêmica.

\section{ACOLHIDA OU APROPRIAÇÃO DISCIPLINATÓRIA?}

Mas nem tudo é tão tranquilo e amistoso nesse processo pelo qual as ciências da saúde passam a respeitar e incorporar práticas terapêuticas holísticas dirigidas à espiritualidade dos pacientes e relacionadas com a New Age. Era previsível que, em algum momento, as ciências médicas mais "ortodoxas" manifestassem suas reservas a esse processo. No Brasil, em uma "Nota à população e aos médicos", tornada pública em 13 de março de 2018, pelo Conselho Federal de Medicina (CFM), a respeito da "Incorporação de práticas alternativas pelo SUS”, manifesta “posição contrária a essa medida”. A instituição argumentava que: "1) Tais práticas alternativas não apresentam resultados e eficácia comprovados cientificamente”) A prescrição e o uso de procedimentos e terapêuticas alternativos, sem reconhecimento científico, são proibidos aos médicos brasileiros, conforme previsto no Código de Ética Médica e em diferentes normas aprovadas pelo Plenário desta autarquia”.

Como se percebe, a ortodoxia médica brasileira levanta questôes a respeito da comprovação científica da eficácia das terapias alternativas, mesmo que, como foi referido acima, uma quantidade expressiva de artigos científicos fornecessem algum respaldo a elas. A questão que se coloca, então, é até que ponto essa literatura é levada a sério por essa ortodoxia médica. Ela não seria, em grande escala, uma literatura produzida por "convertidos" para "convertidos"? Não é improvável que alguns setores das ciências médicas encontrem-se como que seduzidos pela perspectiva "holista" trazida pelas religiosidades New Age e, em funçáo disso, tenham adotado uma postura menos rigorosa em se tratando de construção de evidências comprobatórias para tais práticas. Um levantamento investigatório, a ser feito, sobre esse tipo de vínculo ajudaria bastante a identificar o "lugar de fala" daqueles que, dentro das ciências médicas, se mostram entusiastas das terapias holistas. 
Há também tensões entre os detentores desses saberes terapêuticos e os agentes que, de dentro das ciências da saúde, começam a se apropriar deles. Conforme nos informa Waleska Aureliano (2011), as políticas integrativas têm sido criticadas pelos antigos operadores das práticas terapêuticas que a compóem por sofrerem um visível "controle, normatização e disciplinamento". Essas práticas, "que antes eram dominadas pelos sujeitos em relaçóes terapêuticas cotidianas e regidas por mecanismos de controle próprios de seus praticantes" (Aureliano, 2011, p. 184), passam a ser tuteladas por agentes oficiais das ciências da saúde.

Tradicionalmente, no Brasil, há como que uma postura da "medicina hegemônica" de tratar autoritariamente as práticas concorrentes, aquelas que se apresentam como alternativa; seja para lhe negar real valor terapêutico ou, mesmo, quando lhe interessa, para lhe disciplinar, controlar, normatizar. Paula Monteiro já havia notado esse tipo de postura em 1985, quando percebe algo assim ocorrendo com a chamada "medicina comunitária". Diz a autora:

Cumpre ressaltar que todas as vezes que a Medicina hegemônica se voltou para a compreensão das práticas populares, sobretudo no que diz respeito às tentativas de seu aproveitamento dentro da chamada "medicina comunitária", que pretende treinar "agentes nativos" para o atendimento médico-hospitalar mais imediato, ela o fez no sentido da reapropriaçáo, e conseqüente neutralizaçáo, desses valores em seu próprio esquema de conhecimento e exercício. Desse modo a revalorização das práticas populares se dá no sentido de tornar mais contundente, duradora e eficaz a penetração da Medicina hegemônica, e não no da compreensão e revalorização das práticas mágico-religiosas (Monteiro, 1985, p. 108-109).

No caso mais atual, aqui em questão, das terapias holistas direcionadas à espiritualidade dos pacientes, há também, segundo Aureliano (2011, p. 185), críticas ao esvaziamento dos "conteúdos teórico-filosóficos" dos MTs e MACs ao serem "transpostas para os campos da racionalidade científica que domina os sistemas oficiais de saúde”. São questionados, também, "os modos como se tenta medir a eficácia dessas terapias", bem como "das 
racionalidades médicas nelas envolvidas através de instrumentos e conceitos provenientes da biomedicina que opera com paradigmas completamente diferentes" (Aureliano, 2011, p. 185).

\section{O MERCADO DA ESPIRITUALIDADE}

Vê-se, pelo exposto até aqui, que o emergente cuidado que as ciências da saúde têm dispensado à "espiritualidade", não se faz sem que as tensôes do "mercado religioso" emerjam também, já que se trata de práticas terapêuticas que, em muitos casos, mudam abruptamente de mãos e isso, evidentemente gera contestaçóes sobre a propriedade desses produtos, bem como, sobre a qualidade daquilo que é entregue ao consumidor final, o paciente que faz uso dos sistemas de saúde oficiais. Temos, claramente, o surgimento de um produto híbrido entre a religiosidade New Age contemporânea e ciências da saúde centrada na ideia, relativamente nova nesse segundo campo, de que há uma "natureza humana" que além das propriedades já conhecidas (fisiológicas, morfológicas, químicas, energéticas, psíquicas, etc.) também pressupõe uma "espiritualidade”. Importante, também, viu-se, essas propriedades formariam um arranjo "holístico" que precisa estar harmonizado para que a saúde do paciente fosse restaurada.

Trata-se de um produto oferecido em espaços bastante dessacralizados, nas ascéticas áreas destinadas ao exercício das ciências da saúde (hospitais, clínicas, consultórios, postos de saúde, spas, etc.). Também por se apresentar como um produto que tem um tipo de validação um tanto inusitado, se comparado aos produtos tradicionais disponíveis no mercado religioso, tem sua eficácia testemunhada através de procedimentos afins com a ciência (pesquisas, experiências, publicaçóes científicas, etc.).

Se comparado ao produto náo hibridizado, as práticas terapêuticas das ciências da saúde vinculadas à "espiritualidade" possuem vantagens e desvantagens. Por um lado, ostentam uma certificação altamente valiosa no mundo moderno, a ciência empenha-se em lhe dar credibilidade. Isso 
não é pouco, se levarmos em consideração que durante séculos foi essa forma de conhecimento que corroeu o prestigio das práticas religiosas. Se agora temos um "ex-inimigo" disposto a ceder espaços em seu ceticismo ao campo mágico-religioso, isso, certamente, impressiona. Trata-se, pois, de dois gigantes da cognição humana unidos para emprestar credibilidade a alguns procedimentos terapêuticos bastante acionados nos dias atuais.

Por outro lado, não deixa de ocorrer uma certa perda de aura nesta hibridização de que se fala aqui ou, para usar um termo mais comum aos antropólogos, uma certa perda de mana nesse processo. A percepção esboçada por pesquisadores desse fenômeno de que há contestaçóes de operadores "nativos" dessas terapias quanto a forma de apropriação delas pelas ciências da saúde, além de revelar disputa mercadológica pelo controle do "produto", indica insatisfação com uma certa artificialização do "produto" decorrente da forma cientificizada como é tratado. É como se as ciências da saúde entregassem um produto "industrializado" - cheio de adulteraçóes padronizadoras, ascético, pasteurizado, desencantado, com déficits de energias mágico-religiosas - e o campo New Age algo mais orgânico, nativo, tradicional - cheio de mana reenergizador.

\section{À GUISA DE CONCLUSÃO}

O exame feito até aqui dessa "espiritualidade", que penetra triunfante nos ambientes clínicos e hospitalares, nos diz muito sobre como religiosidades, sensibilidades, práticas terapêuticas do tipo "Nova Era" (New age) se propagam nos tempos atuais.

Em outro texto (Jungblut, 2015) ${ }^{1}$, abordamos algo que parece útil trazer aqui. Trata-se do conceito de "novaerização" proposto por Anthony D'Andrea (1996), que nomeia de forma sintética os vários tipos de processos destradicionalizantes por que passam, na atualidade, diversas tradições religiosas que estão, ou não, organizacionalmente institucionalizadas. Alude também ao processo de autonomização dos indivíduos e pequenos grupos em relação 
a essas tradições e, ainda, o funcionamento organizacional desinstitucionalizado, em rede. Assim, este conceito se mostra algo apropriado para aludir processos variados onde tais agentes disporiam de crescente liberdade para permanecer, transitar, inventar, atuar ecleticamente, produzir bricolagens e/ ou sincretizar os elementos de crença recolhidos do contemporâneo mercado de bens religiosos.

Talvez tenhamos aqui um pouco disso, de "novaerização", se processando por todos os lados. Mas há, contudo, algo novo trazido pela acolhida do termo "espiritualidade" para o interior das percepçóes próprias das ciências da saúde e que contribui para adensarmos ainda mais o escopo daquilo que captado pelo conceito de "novaerização". Um movimento de novo tipo é detectável aqui, a amistosidade de setores de um front da ciência moderna para com algo acoplado ao mágico-religioso. Esse esforço que parcelas das ciências da saúde fazem para acomodar práticas e percepçóes desse tipo, estranhas aos procedimentos científicos, indica estar em processo uma certa permeabilidade do, antes, rígido casco que protege o pensamento racional moderno. As razóes para isso podem ser várias. A ciência, ou setores dela, passam por um processo de flexibilização de seu ceticismo racionalizante? Com o individualismo exacerbado dos nossos dias, os profissionais das ciências da saúde têm mais agência, mais autonomia identitária, e se sentem menos constrangidos por um rigor científico desencantador que reinava absoluto até bem pouco tempo e isso explicaria o contrabando que fazem para dentro do seu campo profissional das práticas terapêuticas da Nova Era? Temos, inegavelmente, como se vê, um novo front dos processos de "novaerização" a investigar. 


\section{REFERÊNCIAS}

AURELIANO, Waleska de Araújo. Espiritualidade, saúde e as artes de cura no contemporâneo: indefinição de margens e busca de fronteiras em um centro terapêutico espírita no sul do Brasil. 2011. Tese (Doutorado em Antropologia Social) - Universidade Federal de Santa Catarina, Florianópolis, 2011.

BELLAH, Robert. A nova consciência religiosa e a crise na modernidade. Religiâo \& Sociedade, Rio de Janeiro, v. 13, n. 2, p. 18-37, 1986.

CAMPBELL, Colin. A orientalização do ocidente: reflexôes sobre uma nova teodicéia para um novo milênio. Religiāo \& Sociedade, Rio de Janeiro, v. 18, n. 1, p. 5-29, 1997.

CARVALHO, José Jorge de. O encontro de velhas e novas religióes: esboço de uma teoria dos estilos de espiritualidade. Brasília, DF: Universidade de Brasília, 1992. (Série Antropologia, 131).

D'ANDREA, Anthony A. F. O self perfeito e a nova era: individualismo e reflexividade em religiosidades pós-tradicionais. 1996. Dissertação (Mestrado em Sociologia) - Instituto Universitário de Pesquisas do Rio de Janeiro, Rio de Janeiro, 1996.

DURKHEIM, Émile. As formas elementares da vida religiosa: o sistema totêmico na Austrália. São Paulo: Paulinas, 1989.

HERVIEU-LÉGER, Danièle. O peregrino e o convertido: a religião em movimento. Petrópolis: Vozes, 2008.

JUNGBLUT, Airton Luiz. New Age-ification. In: GOOREN, Henri (ed.). Encyclopedia of Latin American Religions. Cham: Springer International Publishing, 2015. p. 1-5.

JUNGBLUT, Airton Luiz. O Evangelho New Age: sobre a gnose evangélica no Brasil na visão de seus detratores. Civitas: Revista de Ciências Sociais, Porto Alegre, v. 6, n. 2, p. 101-121, 2006. 
LARAIA, Roque de Barros. Da ciência biológica à social: a trajetória da antropologia no século XX. Habitus, Goiás, v. 3, n. 2, p. 321-346, 2005. MONTEIRO, Paula. Da doença à desordem: a magia na umbanda. Rio de Janeiro: Graal, 1985.

PROCÓPIO, Cândido. Kardecismo e umbanda. São Paulo: Pioneira, 1961. SCHUTZ, Alfred. Fenomenologia e relaçôes sociais. Rio de Janeiro: Zahar Editores, 1979.

TONIOL, Rodrigo. Do espirito na saúde: oferta e uso de terapias alternativas/complementares nos serviços de saúde pública no Brasil. 2015. Tese (Doutorado em Antropologia Social) - Universidade Federal do Rio Grande do Sul, Porto Alegre, 2015a.

TONIOL, Rodrigo. Espiritualidade que faz bem: pesquisas, políticas públicas e práticas clínicas pela promoção da espiritualidade como saúde. Sociedady religión, Buenos Aires, v. XXV, n. 43, p. 110-143, 2015 b.

TONIOL, Rodrigo. O que faz a espiritualidade? Religião \& Sociedade, Rio de Janeiro, v. 37, n. 2, p. 144-175, 2017. 


\section{ÚLTIMAS PUBLICAÇÓES DO AUTOR}

JUNGBLUT, Airton Luiz; ADAMI, Vítor Hugo da Silva. Hinduísmos ocidentalizados e suas percepçóes acerca do sexo: Movimento Hare Krishna e Movimento Rajneesh. Religiäo \& Sociedade, Rio de Janeiro, v. 37, n. 1, p. 104-121, 2017.

JUNGBLUT, Airton Luiz. Ser evangélico en América Latina: elementos para un análisis. Nueva Sociedad, Buenos Aires, n. 260, p. 95-108, 2015.

JUNGBLUT, Airton Luiz. Práticas ciberativistas, agência social e ciberacontecimentos. Vivencia: Revista de Antropologia, Natal, v. 1, n. 45, p. 13-22, 2015.

JUNGBLUT, Airton Luiz. Globalização e religiâo: efeitos do pluralismo global no campo religioso contemporâneo. Civitas: Revista de Ciências Sociais, Porto Alegre, v. 14, n. 3, p. 419-436, 2014.

JUNGBLUT, Airton Luiz. O Evangelho New Age: sobre a gnose evangélica no Brasil na visão de seus detratores. Civitas: Revista de Ciências Sociais, Porto Alegre, v. 6, n. 2, p. 101-121, 2006.

Recebido em: 26/08/2020

Aprovado em: 26/08/2020 